\title{
Darcy Ribeiro y la emancipación universitaria: algunas vinculaciones con la reforma argentina
}

\section{Resumen}

El intelectual brasileño Darcy Ribeiro, reconocido por sus obras antropológicas en diversos países e idiomas es, hasta el momento, escasamente estudiado por sus trabajos y propuestas para la universidad latinoamericana, tanto en Brasil como en Argentina. Por eso, nos disponemos, en la conmemoración de los 100 años de la Reforma de Córdoba, a recuperar parte de su vasta producción sobre el tema. Pues, justamente, las iniciativas de Ribeiro ocurrieron en el transcurso del cincuentenario de aquel acontecimiento en el marco de profundos cambios económicos, políticos, culturales y sociales que exigían una renovación en las políticas académicas de las casas de estudios para el Tercer Mundo. Impulsos que fueron interrumpidos por sendas dictaduras cívico - militares y que demandan, en el incipiente siglo, otra reflexión liminar, distinta a la del Manifiesto de 1918, para una posible y descolonizada transformación, en contextos periféricos y subalternos del conocimiento que buscan su emancipación.

Palabras clave: Reforma Universitaria, Darcy Ribeiro, Pensamiento Fronterizo, Geopolítica del Conocimiento, Tercer Mundo.

\section{Abstract}

The Brazilian intellectual Darcy Ribeiro, recognized for his anthropological works in different countries and languages, studied and proposals for the Latin American university has been studying until now, both in Brazil and in Argentina. That is why, in the commemoration of the 100th anniversary of the Reformation in Córdoba, we are recovering part of its vast production on the subject. For, precisely, Ribeiro's initiatives occurred during the fiftieth anniversary of that event in the context of profound economic, political, cultural and social changes that demanded a renewal in the academic policies of the study houses for the Third World. Impulses that were interrupted by civic - military dictatorships and that demand, in the incipient century, another liminal reflection, different from that of the Manifesto of 1918, for a possible and decolonized transformation, in peripheral and subaltern contexts of knowledge that seek their emancipation.

Keywords:University Reform, Darcy Ribeiro, Border Thinking, Geopolitics of Knowledge, Third World.

POR MARTÍN AVEIRO Doctor en Humanidades y Artes, mención en Ciencias de la Educación, por la Universidad Nacional de Rosario, con doctorado sándwich en la Universidade Estadual de Campinas. Es Profesor-Investigador Adjunto regular en el Departamento de Humanidades de la Universidad Nacional del Sur. Sus investigaciones versan sobre historia y pensamiento educativo latinoamericano. lic.aveiro@gmail.com 


\section{Introducción}

El brasileño, oriundo de Montes Claros en Minas Gerais, Darcy Ribeiro (1922 - 1997), que se autodenominaba "antropologiano" en lugar de antropólogo para expresar su condición subalterna en la geopolítica del conocimiento, fue un intelectual latinoamericano que hablaba y escribía desde el Tercer Mundo como un locus poderoso de enunciación. Por ende, vivió en la permanente tensión de saberse objeto de estudio, por su pertenencia a una población colonizada, y sus pretensiones de transformarse en sujeto de conocimiento de la denominada ciencia universal desde una perspectiva periférica (Mignolo, 2011; Miglievich - Ribeiro, 2012). Es en ese sentido que cobran relevancia sus propuestas de reforma universitaria, en clave emancipatoria, para la superación del atraso histórico en el desarrollo social y económico de los pueblos que la mantenían con su esfuerzo y, a su vez, para que aportaran en la construcción de su propia identidad (Dorigão, 2015; Aveiro, 2011; Ribeiro, 1973).

Sus vínculos con Argentina comenzaron el día en que los militares que lo enviaron al exilio, en 1964, lo hicieron latinoamericano. Así, su visión de brasileño se transformó en latinoamericanista (Zea, 1996; Carli\& Aveiro, 2015). Si bien el pequeño avión que lo trasladaba en su huida hacia Buenos Aires no llegó a destino y tuvo que aterrizar en Salto, Uruguay, obligándolo a pedir asilo político para, luego, trasladarse a Montevideo y trabajar en la Universidad de la República, sus libros comenzaron a editarse y difundirse en ambas orillas del Río de la Plata (Miglievich - Ribeiro, 2011; Celentano, 2012). Llegaba a las costas montevideanas después del "experimento" Brasilia ${ }^{1} \mathrm{y}$, enseguida, se ponía a colaborar con Oscar Maggiolo en su plan de reforma de la universidad uruguaya. De allí surgeel texto La universidad latinoamericana (1968), con prefacio de Maggiolo, que fue utilizada para un seminario sobre estructura universitaria dirigido por Ribeiro (Carli \& Aveiro, 2015). Del cual dijo, el filósofo y ex - rector de la Universidad de Buenos Aires, Risieri Frondizi, en su libro La universidad en un mundo de tensiones (1971), que era: "una de las pocas obras orgánicas sobre la universidad latinoamericana actual" (p. 324). También en la banda oriental terminó algunas de sus obras antropológicas cumbres como Procesos civilizatorios (1968) y Las Américas y la civilización (1969).

Así y todo, nos llama la atención como hasta hace poco tiempo no despertaba el interés de los investigadores, especialmente brasileños, el estudio de las iniciativas de transformación de las universidades de Darcy Ribeiro, salvo contadas y aisladas excepciones. Por ejemplo, en su tesis de doctorado, Antonio Marcos Dorigão hizo un relevamiento de la Revista Brasileira de História da Educação (RBHE) y de la Revista Brasileira da Educação (RBE), publicaciones oficiales de la Sociedade Brasileira de História da Educação (SBHE) y de la Associação Nacional de Pós-graduação e Pesquisa em Educação (ANPED), entre 1996 y 2011, en que constan tan solo 6 publicaciones referidas al tema. Además,de los 11 libros localizados en la plataforma electrónica de la Fundación Darcy Ribeiro (FUNDAR), desde 1997 a 2010, ninguno de ellos trata específicamente sobre la problemática universitaria (2015). Algo similar ocurría en la Argentina, dado que la preocupación aparece recientemente en diversas publicaciones e investigaciones. Por eso, vamos a volver a posar la mirada, una vez más, en el autor minero, durante el umbral de un siglo de reformas universitarias que se iniciaron en Córdoba pero que tuvieron diversas expresiones en el transcurso de la historia de ambos países y en el resto del continente.

\section{Un intelectual que incomoda}

¿Será que el descuido de nuestros investigadores, en el análisis de la obra sobre universidades de Darcy Ribeiro, se debe a la incomodidad que les provoca, una vez que acceden al apacible descanso de obtener sus cátedras por concurso o encuentran el modo adecuado de encajar en el repertorio científico y sus exigencias? No obstante, ¿puede un intelectual vivir apoltronado en aquellas comodidades académicas sin repensar el sentido de las instituciones que transitan o utilizarlas, solamente, en beneficio propio? Nuestro "antropologiano" respondería, contundentemente, que no. Es más, le decía al rector Cristóvam Buarque en la reapertura democrática de la Universidad de Brasilia en 1984 - aquella que él mismo ayudó a fundar en la década del sesenta junto con Anísio Teixeira- pasados 20 años de dictadura cívico - militar: 
Ciência falsa e mediocridade nada são, nada podem. No caso da universidade, este desafio científico aponta para o dever de evitar que se cultive um saber fútil, inútil. Que sejaesse Saber de brincadeira de tantos acadêmicosuniversitários, em que umescreve para o outro ${ }^{2}$ (Ribeiro, 1986: p. 20).

Sus posiciones caminaban siempre por un borde que no terminaba de agradar a sus pares científicos ni a los compañeros de militancia política. Aquellos, porque pretendían un mayor virtuosismo metodológico. Los otros, porque le exigían el testimonio, la denuncia y un programa normativo. En cambio, Ribeiro buscaba ser útil a otro tipo de espectador: "aquele que esperavamais da ciência e era, ao mesmo tempo, mais exigente com a ação"3 (Miglievich - Ribeiro, 2012:p. 292). En su último libro, O povo brasileiro,llegó a manifestar:

Portanto, não se iluda comigo, leitor. Além de antropólogo, souhomem de fé e de partido. Faço política e façociência movido por razões éticas e por um fundo patriotismo. Não procure, aqui, análisesisentas. Este é umlivro que quer ser participante, que aspira a influir sobre as pessoas, que aspira a ajudar o Brasil a encontrar-sea si mesmo $^{4}$ (Ribeiro, 2002: p. 17).

El territorio lindero en el que se ubicaba, que tensionaba los límites entre la academia y la política, representaba una ventaja en cuanto a la defensa y la realización de sus ideas, pero, a su vez, era vulnerable a las críticas de sus adversarios quienes le endilgaban apego al poder, vanidad y faltas de lealtad con quienes lo apoyaban. Si bien, las tesis que tratan su obra y actuación pública la definen como diversificada por los campos de trabajo que lo ocuparon, rica en producción, en búsqueda constante de resultados por la práctica científica, distante de meros academicismos y con gran capacidad discursiva para convencer a pares y oponentes. En cuanto a las adaptaciones que realizó a lo largo de su vida, siempre envuelto en proyectos políticos de gran exposición mediática, con una personalidad fuerte y llena de contradicciones, que lo hacían reacio al purismo del discurso académico - por eso, también pueda explicarse, la ausencia de suficientes trabajos que aborden sus propuestas universitarias -, él mismo se mofaba al hablar de sus pieles que, como la ecdisis de las serpientes, mudan (Dorigão, 2015).

\section{Configuraciones teóricas originales e integraciones políticas}

La formación en la Escuela Libre de Política y Sociología de São Paulo, bajo la impronta liberal de Fernando de Azevedo (1894 - 1974) y la tradición norteamericana de la Escuela de Chicago a través de Donald Pierson (1900 - 1995), lo envolvieron en la imposibilidad de pensar a la ciencia por la ciencia misma sin intervención social. Asimismo, el encuentro, primero reacio, y luego de profunda amistad, con Anísio Teixeira (1900 - 1971), que había recibido la influencia del pragmatismo estadounidense en la Universidad de Columbia, donde enseñaba John Dewey, marcaron el rumbo de sus proyectos educativos (2015). Cuestiones que jalaban de una punta de su pensamiento, en torsión de fuerza, con el otro extremo de donde tiraba su inclinación por el Partido Comunista - al que más tarde renunció por el impacto que le provocó el testamento de Getúlio Vargas antes de quitarse la vida (Pinheiro, 2012) - y su pasión por los pueblos indígenas de Brasil, que lo colocabanen los bordes entre los procesos civilizatorios y el salvajismo:

Pero no piense el lector que abogo por el retorno a la Barbarie. Lejos de mí tamaño disparate. Lo que tengo es una nostalgia incurable de un mundo que bien podía ser, pero jamás fue y no sé cómo sería, y si lo supiese no lo diría (Ribeiro, 1995: p. 175).

Es decir, de un lado el advenimiento de lo que denominó "revolución termonuclear" que debía ser enfrentada con una universidad emancipada, que no repitiera la "modernización refleja" de las clases dominantes, propietarias de las nuevas tecnologías. Del otro, las "venutopías" de un proceso civilizador emergente, asentado en las culturas originarias, que promoviera un futuro privilegiado en esta provincia de la tierra para que sea libre, próspera y solidaria. Una nueva Roma, mejor que las otras, lavada en sangre de indio, que en lugar de absorber europeidades sea más alegre y más 
feliz (Ribeiro, 2002; Aveiro, 2011). Así es, estas combinaciones teóricas lo condujeron hacia un marxismo "a su manera", heterodoxo, que lo llevaron a cuestionar ciertos mecanicismos. Realizó una relectura original de Marx y de Engels. Rechazaba las secuencias evolutivas lineales para enfatizar las rupturas en las configuraciones sociohistóricasde los pueblos latinoamericanos (Miglievich - Ribeiro, 2012):

Además de las posiciones clasistas, existen y persisten otras tensiones como las interétnicas, que son más antiguas y, en muchos casos, más fuertes y hasta más dinámicas. En efecto, las primeras sociedades clasistas aparecieron hace cerca de seis mil años, mientras que las identificaciones étnicas y los conflictos resultantes de sus oposiciones son mucho más antiguas (Ribeiro, 1984: p. 29).

No era el único aspecto en el que sus posturas ideológicas diferían de los filósofos teutones. Pues, aquellos esquemas habían servido para explicar el mundo europeo, pero no las experiencias brasileras. Por ejemplo, las disputas entre una burguesía progresista con las aristocracias feudales o los enfrentamientos de bloques antagónicos en los debates nacionales y populares, dado que Marx preveía el fin de los nacio- nalismos. Por ende, aplicar, sin mediación crítica, las clasificaciones de la historia europea implicaban, según su criterio, caer en una clara violencia epistémica (2012). Veamos, ahora, como todos estos entramados de distinta procedencia, en algunos casos empírica, en otras filosóficas, se amalgamaban en la creación de una universidad necesaria para sociedades subalternizadas.

\section{Universidades emancipadas dentro de proyectos nacionales}

Luego de la comprensión alcanzada por sus estudios antropológicos y de involucrarse decididamente en el campo educativo a través del Instituto Nacional de Estudios Pedagógicos (INEP), de la mano de Teixeira, Darcy Ribeiro emprendió la tarea de pensar un modelo de universidad que les permitiera a los pueblos que las mantenían comprenderse y realizarse de forma independiente. Sin embargo, una casa de estudios no podía pensarse en sí y para sí, en tanto archipiélago disperso y sin articulaciones, sino en función del servicio que le debían al esfuerzo de las poblaciones que las mantienen. Por eso, los proyectos universitarios en los que notamos su incidencia los podemos identificar, entre otras experiencias, con: la Universidad de Brasilia, en el nacional-desarrollismo de João Goulart; la Universidad Nacional de Cuyo, durante el tercer gobierno peronis-

Diva desnuda, detalle, óleo sobre tela, 110×130 cm.

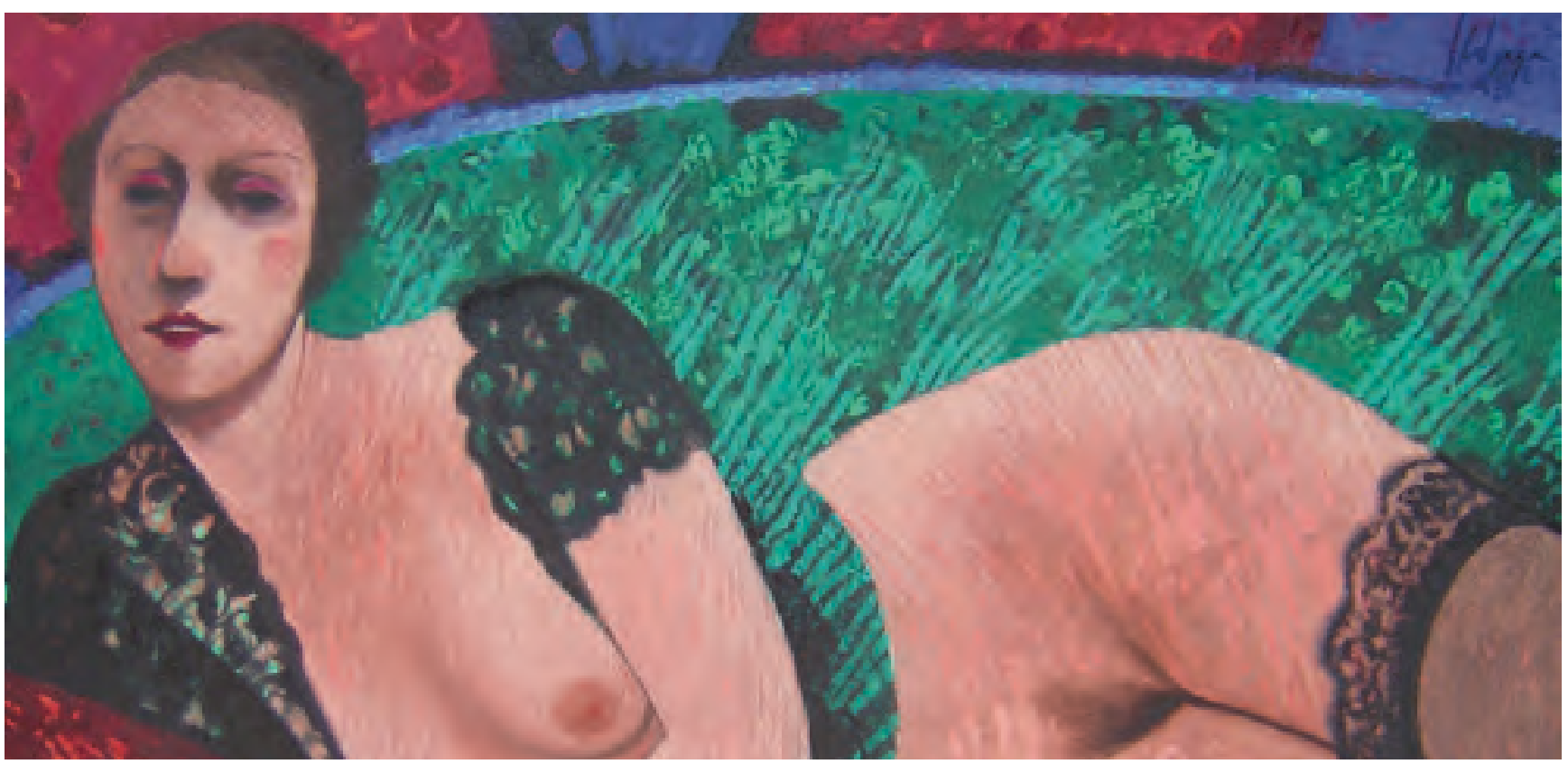


ta; la reforma de las universidades peruanas, con el presidente nacionalista Velasco Alvarado; la creación de la Universidad Nacional en el estado benefactor costarricense, en el tercer mandato de José Figueres Ferrer; o, la Universidad de Ciencias Humanas, en la administración independentista de Argelia con Houari Boumédiène (Carli \& Aveiro, 2015). Es más, en la reconstrucción argelina, liberada de la colonización francesa, las humanidades estaban en el centro de la comprensión y afianzamiento de la conciencia nacional (Villegas, 1992). Cada una de esas tentativas, con sus particularidades, pusieron en crisis la noción clásica de autonomía universitaria, dado que para Ribeiro era uno de los principios más falaces del credo liberal:

Este principio pudo ser magnificado y sacralizado porque, al ser la Universidad intrínsecamente solidaria con el viejo orden social, su aparente no compromiso era la mejor forma de hacerla servir a los intereses dominantes. Confluyeron para ello, múltiples factores. Esencialmente la postura elitista de la mayoría de los profesores provenientes de las capas más abonadas o incorporadas a la élite y, por último, fieles a sus intereses. Y, además, la connivencia de la mayoría de los estudiantes con la universidad tal cual es, conscientes de que, una vez graduados, tendrían ineludiblemente que aquietarse para buscar empleos en los escalones correspondientes a su rango; es decir, a colocarse al servicio de las capas dominantes y de la estructura de poder vigente (Ribeiro, 1974: p. 51).

De alguna manera, al establecer límites a un precepto tan afianzado en las universidades latinoamericanas, luego de la reforma de Córdoba en 1918, se inclinaba, en contextos de gobiernos populares, hacia los modelos derivados del socialismo soviético, expresados en Cuba, por ejemplo. No obstante, a la hora de definir una estructuración interna que articule la universidad en sus partes y en la integración de sus políticas académicas - docencia, investigación y extensión o servicios a la comunidad - defendía, con sus adecuaciones, el arquetipo de departamentalización norteamericano frente a la tradición medieval que imperaba con sus estructuras de cátedrasburocráticas, tendientes al favoritismo y el aislamiento (1973). Aun así, se diferenciaba de los impulsos que llevaba a cabo el estadounidense Rudolph Atcon, y su estudio sobre $L a$ Universidad Latinoamericana que, en los años sesenta, era leído y consultado por rectores y funcionarios de la región (Roig, 1998). Para Ribeiro, sus finalidades estaban teñidas de un tecnocratismo tendientes al privatismo y a la despolitización que consideraba absurdos. En su lugar, sostenía la contrapolitización de las universidades y la necesidad de que fueran solventadas por el estado (1973).

La producción escrita de Darcy Ribeiro es intensa a lo largo de su vida. Según Dorigão (2015), publicó 42 libros y decenas de artículos, folletos y relatos que abarcaron las más diversas temáticas: literatura, educación, antropología, etnografía, sociología y biografías difundidos en distintos países e idiomas (Pinheiro, 2012). Algunas de las cuales, numerosas, se ocuparon específicamente de las universidades y que, a diferencia de sus escritos antropológicos, significativamente no fueron editadas en los Estados Unidos ni en Europa (Celentano, 2012). El punto de partida, por supuesto, era la Universidad de Brasilia, organizada en base a dos lealtades: por un lado, los valores y patrones internacionales de la ciencia y la cultura y, por otro, el pueblo y la nación (Aveiro, 2013). El primer aspecto se relacionaba con aquello que mencionamos al comienzo de convertirse, desde la periferia, en un sujeto de conocimientos a escala global. El segundo, con la superación del atraso frente al cual la universidad no podía ser connivente. Para ello, era preciso crear un centro activo que analice los problemas nacionales y proponga soluciones y, a su vez, que forme el personal calificado, en cantidad y variedad, en las especialidades necesarias del crecimiento autónomo (2015).

\section{Nuevas reformas universitarias, ante el agotamiento de "la Reforma"}

Después de transcurrido medio siglo de la Reforma Universitaria argentina y en el marco de los cambios económicos, políticos, culturales y sociales que se sucedieron en la década del sesenta, Ribeiro entendía que era necesaria una nueva transformación de las universidades latinoamericanas. Partía del reconocimiento de los logros reformistas, entre ellos la gestión participativa, pero afirmaba que no alcanzaba para lograr una universidad integrada, comprometida con las realidades nacionales y donde el saber circulara democráticamente sin estar atado a la vetusta estructura 
de cátedras. Es más, Arturo Roig quien, en base a los estudios del brasileño, desde la secretaria académica de la Universidad Nacional de Cuyo impulsó la segunda gran reforma de la universidad argentina en 1973, decía que aquel proyecto de los jóvenes del 18 había fracasado y que había que reemplazarlo por otro que superara el sistema de cátedras y la extensión universitaria, en tanto modo exclusivo de acercarse al pueblo (Aveiro, 2014).

El problema de fondo, que atravesaba la búsqueda de modificaciones al modelo universitario vigente hasta entonces, era la revolución tecnológica en ciernes, más profunda que la revolución industrial sobre la cual se plasmó la primera reforma universitaria. Pues, tenían como fuerza avasalladora de acción corporaciones transnacionales que llegaban a definir, inclusive, los temas de investigación científica de los países subalternos y convertía en un mito las libertades académicas (Aveiro, 2011; Dorigão, 2015):

Se uma vez mais nos deixaramosfazer consumidores de seus frutos, em lugar de dominadores de suatecnologia nova, as ameaças sobre a nossa sobrevivencia e sobre a soberania nacional serãoaindamais intensas. As classes dominantes e seusporta-vozesjádefiniramseuprojeto de continuidadeatravés das transformações estratégicas. Tal é o discurso neoliberal e privatista ${ }^{5}$ (Ribeiro, 2002: p. 262).

Por ello, postulabala construcción de una universidad necesaria, la cual había quedado inconclusa en Brasilia, y que fue el tema de uno de sus libros editado en Buenos Aires en 1967 por Galerna, la primera publicación del autor en nuestro país (Celentano, 2012; Dorigão, 2015; Miglievich - Ribeiro, 2017). Aquella casa de estudios debía ser incluyente, hasta el extremo de una meta lejana: "abrir la Universidad a la totalidad de los jóvenes de cada generación" (Ribeiro, 1974: p. 242). Y, al mismo tiempo, atenta a las demandas diversificadas de la población estudiantil, que no podían ser consideradas como un todo homogéneo,e implicaba diferenciarlos en: consumidores, profesionalistas, académicos y especiales. Los consumidores eran aquellos que aún no definían, claramente, su elección profesional y precisaban de un acompañamiento 
específico. Los profesionalistas iban en busca del diploma que los habilitase a trabajar, sin pretensiones científicas o académicas y a los que no se les podía exigir cuestiones al respecto. Este tipo de estudiantes precisaba de evitar obstáculos que obturaran el tiempo de obtención del título habilitante e, inclusive, cursos nocturnos y cargas horarias distintas a las del resto, de acuerdo con sus posibilidades efectivas. Luego, el académico, sobre quien recaía una dedicación exclusiva al estudio, con vinculación obligatoria en proyectos de investigación e implicaba, en algunos casos, becas completas para sustentar sus gastos. $\mathrm{Si}$ bien, estos tres tipos de estudiantes pasaban por un ciclo básico común antes de la elección de sus respectivas carreras (2017). Finalmente, estaba la figura de los estudiantes especiales que podían inscribirse a las clases de una sola asignatura de cualquier curso y no se les exigía ninguna formalidad, ni siquiera la escuela primaria, sino, simplemente, demostrar ante el Departamento en que se incorporaban seguir con provecho las temáticas por las que optaban.

Más de un crítico de la Universidad de Brasilia advirtió que por esta puerta ancha y democrática de los "estudiantes especiales", la Universidad terminaría viendo sencillos albañiles asistir a sus cursos de construcción civil. Lo que extraña es pensar que no haya sido precisamente para eso que abrió sus puertas (Ribeiro, 1971: p. 180).

Aquellos importantes avances en la nueva e incipiente reforma de la universidad latinoamericana fueron abruptamente interrumpidos por la dictadura brasileña casi en sintonía con la clausura del reformismo argentino durante el gobierno de facto de Juan Carlos Onganía. Así es, después de expulsar de la UnB a los "marxistas" que la pergeñaron, bajo el comando de Darcy Ribeiro, y de una breve intervención de Zeferino Vaz, que prometió y no cumplió mantener lo realizado, las depuraciones continuaron con su reemplazante Laerte Ramos de Carvalho. La consecuencia fue la dimisión voluntaria de 223 profesores en 1965 , el primer caso en el mundo (2017). Le siguió, en 1966, la renuncia masiva que se produjo en la Universidad de Buenos Aires, luego de la clausura del gobierno tripartito y "la noche de los bastones largos", que puso fin al romance entre la democracia restringida, con interregnos dictatoriales, y el reformismo universitario que se había reinstalado en la sociedad argentina desde 1955. Lo cual obligó al estrechamiento entre sectores antes enfrentados, como el movimiento estudiantil y el de los trabajadores, quienes confluyeron en diversos estallidos sociales para luchar contra la dictadura y obligarla a la retirada. El mayor enfrentamiento se produjo en la misma ciudad que 50 años antes había acunado la Reforma y fue denominado "Cordobazo". En cambio, en Brasil, si bien los estudiantes junto a las organizaciones gremiales se movilizaron en contra del gobierno autoritario, como sucedió con la "marcha de los cien mil" en Río de Janeiro, no pudieron debilitar un régimen que se mantuvo 20 años en el poder. Con todo, Darcy Ribeiro, además de hacerse latinoamericanista en el exilio, sembró universidades. Algunas dieron sus frutos, otras fueron el blanco privilegiado de los sectores reaccionarios de las sociedades que las cobijaron, como la nuestra (Aveiro, 2014).

\section{Consideraciones finales}

Decía el escritor y político brasileño que había vivido como un zapatero remendón, en tanto exiliado, poniendo medias suelas en las universidades de todas partes (Ribeiro, 1986). El destierro lo transformó en un intelectual en tránsito, que se afirmó en una nueva dimensión, el latinoamericanismo, que en lugar de aislarlo le dio un sentido de pertenencia a su existencia y le permitió ensanchar sus redes, con su presencia y con sus escritos como una forma de reinventarse y de reinventar el mundo (Miglievich - Ribeiro,2011; 2017). En la coyuntura internacional de la Guerra Fría, entre las décadas del sesenta y setenta, el Cono Sur se vio envuelto en dictaduras cívico-militares mediante la Operación Cóndor. Primero Paraguay y, enseguida, Brasil hicieron que muchos escaparan hacia Uruguay, Argentina y Chile. Aunque, como en una especie de dominó, los golpes de estado se sucedían por donde pasaban(2011). En ese "entrelugares", su nación deslocalizada y los lugares de peregrinaje, Ribeiro crea y recrea universidades, en textos y en prácticas desde un "pensamiento fronterizo" en una "geopolítica del conocimiento" periférica: 
El pensamiento fronterizo, desde la perspectiva de la subalternidad colonial, es un pensamiento que no puede ignorar el pensamiento de la modernidad, pero que no puede tampoco subyugarse a él, aunque tal pensamiento moderno sea de izquierda o progresista. El pensamiento fronterizo es el pensamiento que afirma el espacio donde el pensamiento fue negado por el pensamiento de la modernidad, de izquierda o de derecha (Mignolo, 2011, p. 51).

Otra reflexión liminar, distinta a la del Manifiesto del 18, se alzaba en la década del sesenta del siglo XX para situar la institución universitaria, como producto de la modernidad con algunas herencias feudales. Era: “[...] el súbito descubrimiento de que todo es cuestionable, de que las viejas explicaciones eran justificaciones, de que hay que repensarlo todo" (Ribeiro, 1973: p. 11). La apertura de nuevos umbrales de percepción, frente a las alteraciones estructurales por las que atravesaban y ante la cual se hacía imprescindible un remapeo de las culturas del conocimiento para la superación del totalitarismo epistémico de la modernidad/colonialidad (Miglievich - Ribeiro, 2013).

Ahora bien, veamos cuales son las continuidades y rupturas entre aquella gesta de 1918 y las reformas impulsadas por Darcy Ribeiro. En principio, resignificar la autonomía universitaria, de vital importancia ante el mecenazgo privado, la sujeción eclesial o cualquier injerencia de los poderes gubernamentales o de instituciones extranjeras que limiten su autogobierno (Aveiro, 2015; 2011).De cualquier modo, el funcionamiento autónomo debía corresponderse con el necesario servicio hacia la sociedad que la mantiene y, todavía más, la colaboración hacia gobiernos populares en el estudio y resolución de los problemas que aquejan al país. Seguidamente y relacionado a lo anterior, el co-gobierno, en su necesaria politización y gestión participativa, con los cuidados de no transformarse en elites reaccionarias contrarias a los intereses de las mayorías. En tanto puede arrogarse la representación ilustrada como, lamentablemente, ha sucedido en determinados casos (TünnermanBernheim, 2008). Cuestiones que se resuelven desde dos ángulos complementarios: uno académico - pe- dagógico, a través de la superación de la estructura de cátedras y, el otro, con la incorporación masiva de las juventudes a los estudios superiores. Ninguno de estos problemas había estado presente en los pedidos estudiantiles de Córdoba. Pues, la cátedra aún rige la organización de las políticas académicas en gran parte de las universidades latinoamericanas y, a su vez, aquella reforma no dejó de ser para las capas medias y altas de la población, la incorporación de los estratos más bajos fue muy posterior y todavía queda mucho por realizar al respecto.

Para cerrar, las reformas universitarias que impulsaba Darcy Ribeiro se proponían quebrar con antiguos prejuicios que oponían cantidad y calidad de la educación superior. Y, fundamentalmente, que dejaran de ser reductos de entrenamiento de los "cachorros del sistema” (Ribeiro, 1972: p. 9), el útero en el cual la clase dirigente se reproduce en carreras que los califican para "no ser pueblo", perfectos guardianes del sistema. Esa es su mayor eficacia, ser una máquina de convertir a las personas en "no - pueblo" (Ribeiro, 1978). Por eso, el principal desafío que nos transmite Ribeiro, de cara al centenario reformista, es reconocer las diferencias, las heterogeneidades, de la población que habita nuestras casas de estudios en el siglo XXI. Sobre todo, aquel proletariado estudiantil, provenientes de las capas sociales más pobres y menos "cultas", que "encuentra dificultades hasta para convivir [...], con las eminencias de la comunidad universitaria”, sin los cuales no puede haber una democratización efectiva de las instituciones (Ribeiro, 1974: p. 174). Es decir, comprender el horizonte en que se entretejen las demandas de los jóvenes, en contextos fragmentados, con las bases institucionales asentadas hace un siglo y las lógicas de éstas con la dinámica compleja de lo social (Krotsch, 2014). Por consiguiente, revitalizar el movimiento reformista implica asumir críticamente su historia y el compromiso, en un aquí y un ahora de las universidades latinoamericanas, de una posible y descolonizada transformación, en contextos periféricos y subalternizados del conocimiento que buscan su emancipación. 


\section{Notas}

1. Ver Aveiro (2011), p. 15 - 19.

2. "Ciencia fala nada son, nada pueden. En el caso de la universidad, este desafío científico apunta para el deber de evitar que se cultive un saber fútil, inútil. Ese saber de broma de tantos académicos universitarios en el que uno escribe para el otro" (Trad. propia).

3. "aquel que esperaba más de la ciencia y era, al mismo tiempo, más exigente con la acción" (Trad. propia).

4. "Por lo tanto, no se engañe conmigo, lector. Más allá de antropólogo, soy hombre de fe y de partido. Hago política e hago ciencia movido por razones éticas y por un profundo patriotismo. No busque, aquí, análisis neutros. Este es un libro que quiere ser participante, que aspira a influir en las personas, que aspira a ayudar a el Brasil a encontrarse a sí mismo" (Trad. propia).

5. "Si una vez más nos dejamos hacer consumidores de sus frutos, en lugar de dominadores de su nueva tecnología, las amenazas sobre nuestra sobrevivencia y sobre la soberanía nacional será todavía más intensa. Las clases dominantes y sus portavoces ya definieron su proyecto de continuidad a través de transformaciones estratégicas. Tal es el discurso neoliberal y privatista”. (Trad. propia).

\section{Bibliografía}

Aveiro, Martín (2011) "Darcy Ribeiro: procesos civilizatorios y universidad", en Cuadernos Americanos, año XXV, vol. 2, núm. 136, pp. 11 - 44. México: Universidad Nacional Autónoma de México.

(2013) "Políticas académicas en dos pensadores latinoamericanos: Darcy Ribeiro y Arturo Andrés Roig”, en Roteiro, [S1], julio, pp. 89-108. Disponible en:http://editora.unoesc.edu.br/index.php/ roteiro/article/view/2489 (23 de octubre de 2017).

(2014) La universidad inconclusa. De la Ratio Studiorum a la reforma universitaria en Mendoza (1973 - 1974). Mendoza: EDIUNC.

(2015) "Darcy Ribeiro: de la universidad connivente a la universidad necesaria en América Latina”, en Arpini, Adriana (Coord.). El humanismo, los humanismos. Ideas y prácticas revisadas desde nuestra América. Mendoza: EDIUNC.

Carli, Sandra y Aveiro, Martín (2015) "A propósito de Darcy Ribeiro: conexiones e intercambio de ideas y experiencias universitarias con intelectuales argentinos", en Pimenta Rocha, Heloísa Helena y Borges Salvadori, María Angela (Org.). Entre Brasil y Argentina: miradas sobra a história da educação. Belo Horizonte: Fino Traço.

Celentano, Adrián (2012) "De la universidad necesaria a la universidad nueva: la recepción argentina de las tesis de Darcy Ribeiro entre 1967 y 1973", en Jornadas de Sociología de la UNLP, 2., Actas (VII 2012), pp. 1-22. La Plata: FahHCE.

Dorigão, Antonio Marcos (2015) Darcy Ribeiro e a reforma da universidade: autonomia, intencionalidade e desenvolvimento. Tesis doctoral, Centro de Ciências Humanas, Letras e Artes, Programa de Pós-graduação em Educação, Área de Concentração: Educação. Maringá: Universidade Estadual de Maringá.

Frondizi, Risieri (1971) La universidad en un mundo de tensiones: misión de las universidades en América Latina. Buenos Aires: Paidós.

Krotsch, Pedro (2014) "Los universitarios como actores de reformas en América Latina: ¿han muerto los movimientos estudiantiles?”, en Carli, Sandra (dirección y compilación) Universidad pública y experiencia estudiantil. Historia, política y vida cotidiana. Buenos Aires: Miño y Dávila, pp. 141 - 163.
Mignolo, Walter (2011) Historias locales / proyectos globales. Colonialidad, conocimientos subalternos y pensamiento fronterizo. Sevilla: Akal.

Miglievich - Ribeiro, Adelia (2011) "Intelectuais no exílio: onde é a minha casa?", en Dimensões, vol. 26, pp. 152 - 176. Disponible en: https:// www.academia.edu/30088287/Intelectuais_no_ex\%C3\%ADlio_ onde_\%C3\%A9_a_minha_casa (15 de octubre de 2017).

(2012) "Darcy Ribeiro e a crítica pós-ocidental de Walter Mignolo: notas sobre procesos civilizatóriosnas Américas”, en Dimensões, vol. 29, p. 281 - 308. Disponible en: http://www.periodicos.ufes. br/dimensoes/article/viewFile/5409/3995 (14 de octubre de 2017).

(2014) "Por umarazãodecolonial. Desafios ético-políticoepistemológico à cosmovião moderna”, en Revista de CiênciasSociais, vol. 14, núm. 1, enero - abril, pp. 66-80. Porto Alegre: PontifìciaUniversidadeCatólica do Rio Grande do Sul.

(2017) “Darcy Ribeiro e UnB: intelectuais, projeto e missão”, en Ensaio: avaliação e políticas públicas em educação, vol. 25, núm. 96, p. 585-608. Disponible en: http://www.scielo.br/pdf/ensaio/ v25n96/1809-4465-ensaio-S0104-40362017002500939.pdf (31 de octubre de 2017).

(2017) "Darcy Ribeiro no exíliolatino-americano: deslocamentos de retina e escritas em trânsito", en Anais do XV Encontro do ABRALIC, experiências literarias textualidades contemporáneas. Disponible en: http://www.abralic.org.br/anais-artigos/?id=1164 (1 de noviembre de 2017).

Pinheiro, Lucas Miranda (2012) El ingenioso caballero" Darcy Ribeiro: a trajetória de um "intelectual andante" na cultura política utópica do Brasile da América Latina. Tesis de doctoral, Programa de Pósgraduação da Faculdade de Ciências Humanas e Sociais da Universidade Estadual Paulista "Julio de MesquitaFilho". Francia: UNESP.

Ribeiro, Darcy (1971) La universidad latinoamericana. Caracas: Ediciones de la Biblioteca Universidad Central.

(1972) "Mesa redonda: La universidad en América Latina", en Frondizi, Risieri; Vargas, Arturo Jadresic; Maggiolo, Oscar; Ribeiro, Darcy; Storni, Fernando. Revista Ciencia Nueva, año III, núm. 19, pp. 5-9. Buenos Aires: Editorial Ciencia Nueva.

(1973) La universidad nueva, un proyecto. Buenos Aires: Ciencia Nueva.

(1974) La universidad peruana. Lima: Ediciones del Centro. (1978) UnB: invenção e descaminho. Rio de Janeiro: Avenir. (1984) "La civilización emergente", en Nueva Sociedad, julio-agosto, núm. 73. Buenos Aires: Fundación Friedrich Ebert. de Brasilia.

(1986) Universidade para quê? Brasilia: EditoriaUniversidade

(1995) Utopía Salvaje. Nostalgias de la inocencia perdida. Una fábula. Buenos Aires: Ediciones del Sol.

(2002) O povo brasileiro. A formação e o sentido do Brasil. São Paulo: Companhia das Letras.

Roig, Arturo (1998) La universidad hacia la democracia. Bases doctrinarias e históricas para la constitución de una pedagogía participativa. Mendoza: EDIUNC.

Tünnerman Bernheim, Carlos (2008) "El programa de la Reforma Universitaria", en TünnermanBernheim, Carlos. Noventa años de la Reforma Universitaria de Córdoba (1918-2008). Buenos Aires: CLACSO.

Villegas, Abelardo (1992) La universidad en la encrucijada. México: UDUAL.

Zea, Leopoldo (1996) "Darcy y la inmortalidad”, en Cuadernos Americanos, vol. 3, núm. 57, pp. 37-41. México: Universidad Nacional Autónoma de México. 